\title{
Inflation, Inflation Uncertainty, and Growth: Evidence from Ghana
}

\author{
Bernard Njindan lyke', Sin-Yu Ho ${ }^{2}$
}

ABSTRACT

\begin{abstract}
Inflation and inflation uncertainty are critical factors influencing the functioning of markets and thus the efficient flow of economic activities. In this study, we investigated the effects of inflation and inflation uncertainty on growth in Ghana. Unlike the majority of the previous studies, we distinguished the short-run effects of inflation and inflation uncertainty on growth from the long-run effects. Also, unlike the previous studies, we examined whether increases in inflation uncertainty have the same effects on growth as decreases in it. By applying linear and nonlinear specifications to a data set covering the period 1963 to 2015, we found that inflation has both short and long-run negative effects on growth. Inflation uncertainty has a differential short-run effect and a negative long-run effect on growth. Increases in inflation uncertainty hurt growth, while decreases may reverse this pattern, albeit slowly. Both inflation and inflation uncertainty are critical determinants of growth in the country. To promote growth, policymakers should continue to pursue a low inflation target while ensuring minimal inflation uncertainty.
\end{abstract}

KEY WORDS: $\quad$ Inflation; Inflation Uncertainty; Growth; Ghana

JEL Classification: E31; O47; O55; C22

${ }^{1}$ Department of Finance, Deakin University, Australia; ${ }^{2}$ Department of Economics, University of South Africa, South Africa

\section{Introduction}

The level of inflation and its movements over time have been the focus of nearly all central banks around the globe. The key reason is that inflation is a critical determinant of economic growth and societal welfare. In theory, high and volatile inflation hurts growth and welfare, while low and stable inflation enhances them (Dotsey \& Sarte, 2000; Friedman, 1977; Gomme, 1993; Temple, 2000; Tommasi, 1994) - but this is not always the case. For example, Tobin (1965) contends that an increase in inflation uncertainty may increase

Correspondence concerning this article should be addressed to: Bernard Njindan lyke, Department of Finance, Deakin Business School, Deakin University, 221 Burwood Highway, Melbourne Burwood Campus, Victoria 3125, Australia. E-mail: benitoflex@gmail.com per capita capital because households will move assets from non-interest-bearing accounts to real capital accounts, thereby enhancing capital productivity. In essence, high inflation uncertainty may promote capital productivity. In contrast, De Gregorio (1993) argues that inflation could force up the cost of capital, thereby inhibiting capital accumulation and capital productivity, which would in turn slow down long-run growth.

Apart from the separate effects of inflation and inflation uncertainty on growth, other theoretical studies have recognized the joint impact of these variables on growth. Friedman (1977) argues that increases in inflation are associated with inflation uncertainty, which weakens the price mechanism, thereby dampening economic activity and growth. In a formal model, Ball (1992) demonstrates that high inflation generates high 
inflation uncertainty, which translates into even higher levels of future inflation, since the public will begin to doubt the credibility of the monetary authority. This mechanism hurts long-run growth. In contrast, Ungar and Zilberfarb (1993) argue that an increase in the level of inflation creates incentives for the public to devote resources to predicting its future path. In doing so, nominal inflation uncertainty will be lessened. Dotsey and Sarte (2000) argue that increases in inflation generate increases in inflation uncertainty, which enhances precautionary savings, investment and growth by discouraging the demand for real money balances and consumption. Similarly, Aghion and Saint-Paul (1998), and Blackburn (1999) contend that increases in inflation and inflation uncertainty promote growth in models with technological change, and research and development (R\&D).

The empirical literature is not much different from the theoretical literature. The existing studies suggest that inflation and inflation uncertainty could hurt or enhance growth. First, there are studies that mainly focus on the impact of inflation on growth, without controlling for the role of inflation uncertainty. These studies include De Gregorio (1993), Gylfason and Herbertsson (2001), Gillman, Harris, \& Mátyás (2004), and Guerrero (2006), among others. These studies have usually documented a negative impact of inflation on growth. Along this line of study in the literature, others have found evidence in support of a threshold relationship between inflation and growth. For example, in their studies, Sarel (1996), Bruno and Easterly (1998), Khan and Senhadji (2001), López-Villavicencio and Mignon (2011), Kremer, Bick and Nautz (2013), and Yilmazkuday (2013), found inflation to have a negative impact on growth beyond a certain threshold level of inflation. However, below this threshold, inflation affects growth positively or insignificantly, depending upon the country's level of development. Second, there are studies that are mainly concerned with the effect of inflation uncertainty on growth without controlling for inflation. Here, the findings are inconclusive. While some found inflation uncertainty to be associated with positive growth (Baharumshah, Hamzah, \& Sabri, 2011; Bredin, Elder, \& Fountas, 2009; Coulson \& Robbins, 1985; Mohd, Baharumshah, \& Fountas, 2013), others found negative effects (Apergis, 2005; Bredin \& Fountas, 2005; Fountas, Karanasos, \& Kim, 2002; Grier
\& Perry, 2000; Grier, Henry, Olekalns, \& Shields, 2004; Grier \& Grier, 2006; Heidari, Katircioglu, \& Bashiri, 2013). In addition, Neanidis and Savva (2013) find that inflation uncertainty inhibits growth rates in a highinflation regime. Finally, there are studies that have included both inflation and inflation uncertainty in their growth specifications and have found mixed results. For instance, Fischer (1993), and Judson and Orphanides (1999) found a negative impact of both inflation and inflation uncertainty on growth. Conversely, Grier and Grier (2006) found that inflation does not inversely affect growth once inflation uncertainty is accounted for. They argue that the negative impact of inflation on growth is indirectly linked to inflation uncertainty, in line with the Friedman-Ball hypothesis. Barro (2013) found inflation to negatively affect growth, while inflation uncertainty affected it positively.

From both the theoretical and the empirical literature, it is clear that the impact of inflation and inflation uncertainty on growth is not a conclusive matter. Both may affect growth negatively or positively depending upon whether they are treated separately or jointly in the model, or whether the model is based on a developed or a developing country. Additionally, while the separate effects of inflation and inflation uncertainty have been studied extensively, their joint effects have received less attention in the literature (Baharumshah, Slesman, \& Wohar, 2016). Since the twin issues of lower inflation and price stability remain critical to the functioning of economic systems, further probing of the inflation and inflation uncertainty effects on growth is needed to inform macroeconomic decisions. It is worth noting that recent attempts to establish the effects of inflation and inflation uncertainty on growth have mainly utilised high-frequency data (Baharumshah et al., 2011; Fountas et al., 2002; Fountas \& Karanasos, 2007; Grier \& Grier, 2006; Heidari et al., 2013), which may not be readily available in the case of developing countries. Moreover, the economic conditions in developed economies are arguably relevant because they spill over to the rest of the world. It is therefore unsurprising that these studies have mainly focused on developed countries.

This study adds to the growing literature by jointly examining the effects of inflation and inflation uncertainty on growth in the case of a developing country, Ghana. We also explore whether increases in inflation 


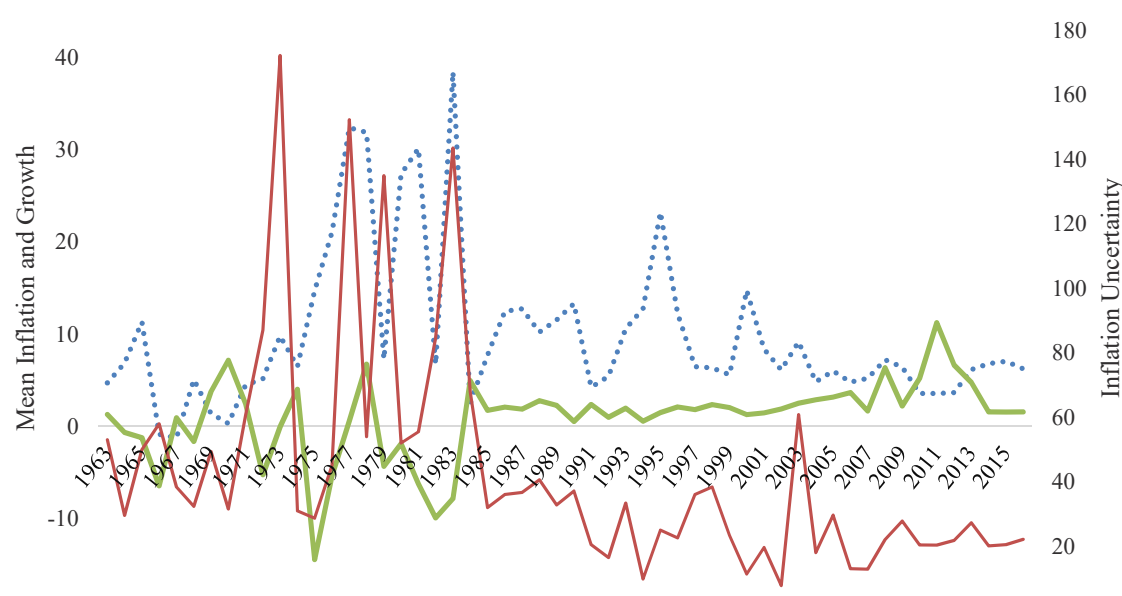

$-20$

0

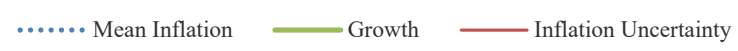

Figure 1. Inflation Uncertainty in Ghana, 1963-2015

Note: Inflation uncertainty is the annualized standard deviation as described in section 3; Mean Inflation is average inflation over 12 months. Growth is year-on-year percentage change in real GDP.

uncertainty have the same effects as decreases. To our knowledge, this is the first attempt at tackling the two issues simultaneously while focusing on a developing country. Ghana has endured frequent episodes of high inflation and inflation uncertainty (Iyke \& Odhiambo, 2017). Inflation uncertainty was severe between 1963 and 1985 and moderate thereafter. The period of severe uncertainty is attributable to political instability, excessive state controls, the severe drought of the 1980s and adverse external developments (particularly the oil price shock of the 1970s), while the moderate period of uncertainty is attributable to the gradual shift to a market economy, political stability, and the adoption of the inflation targeting policy in 2007 (Heintz \& Ndikumana, 2011; Iyke \& Ho, 2017; Licklider, 1988; Owusu, 1989). Figure 1 shows this evidence. Therefore, studies such as this will be useful in explaining the effects of these inflationary conditions on the economy. The findings from this study may also have implications for neighboring countries such as Togo, Burkina Faso and Ivory Coast. Ghana trades with these countries. Hence, improvement in economic conditions in Ghana may have positive spillover effects on these countries. ${ }^{1}$

The rest of the paper is organized as follows. In the next section, we present the methodology. In section 3, we discuss the data and the empirical results. Section 4 concludes.

\section{Methodology}

To assess the effects of inflation and inflation uncertainty on growth, we defined growth as a function of the interest rate, inflation and inflation uncertainty. Our simple model is of the following form:

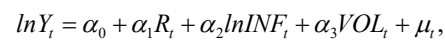

where $Y$ is economic growth; $R$ is the nominal interest rate; INF denotes inflation; VOL is a measure 
of inflation uncertainty; $\ln$ is the natural logarithm operator; $\boldsymbol{\alpha}=\left(\alpha_{0}, \alpha_{1}, \alpha_{2}, \alpha_{3}\right)^{\prime}$ are the coefficients of the model; $\mu$ is the white-noise error term; and $t$ is the time subscript.

In line with the theory, an increase in the nominal interest rate should raise the cost of borrowing and decrease the level of investment and output in the economy (see Mundell, 1963). Therefore, the estimated value of $\alpha_{1}$ should be negative. An increase in the level of inflation is expected to hurt growth (Ball, 1992; Friedman, 1977). Hence, $\alpha_{2}$ is expected to be negative. Inflation uncertainty may hurt or enhance growth (Aghion \& Saint-Paul, 1998; Ball, 1992; Blackburn, 1999; Friedman, 1977). Thus, $\alpha_{3}$ is expected to be either negative or positive.

The limitation of Eq. (1) is that it only permits the study to estimate the long-run impact of inflation and inflation uncertainty on growth. However, the cumulative short-run impacts of these factors on production and consumption are critical in explaining the longrun growth prospects of a country. Therefore, it is important to examine to light the short-run impacts of inflation and inflation uncertainty as well. In a limited data environment, the autoregressive distributed lag (ARDL) framework developed by Pesaran, Shin and Smith (2001) is very suitable for estimating both short and long-run impacts of macroeconomic variables in a time series model. Apart from this important feature, the ARDL framework is also superior in that it does not require pretesting the integration properties of the variables. Hence, it avoids the pretesting bias problem to which other approaches are prone. Additionally, the approach is applicable regardless of whether the variables are $\mathrm{I}(0), \mathrm{I}(1)$, a mixture of both, or are fractionally integrated. A dynamic specification of Eq. (1) in the ARDL setting will be of the following form:

$$
\begin{aligned}
& \Delta \ln Y_{t}=\beta_{0}+\sum_{i=1}^{q} \beta_{1 i} \Delta \ln Y_{t-i}+\sum_{i=0}^{q} \beta_{2 i} \Delta R_{t-i}+
\end{aligned}
$$

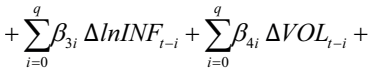

$$
\begin{aligned}
& +\delta_{1} \ln Y_{t-1}+\delta_{2} R_{t-1}+\delta_{3} \ln I N F_{t-1}+\delta_{4} V O L_{t-1}+\epsilon_{t},
\end{aligned}
$$

where $\epsilon, \beta$, and $\delta$ are the white-noise error term, the short-run and the long-run coefficients of the model, respectively; $\Delta$ is the first-difference operator; and $q$ is the maximum lag of the model. The short-run ef- fects are the coefficients of the first-differenced variables. The long-run effects are obtained by setting the non-first-differenced lagged component of Eq. (2) to zero and normalizing $\delta_{2}$ to $\delta_{4}$ on $\delta_{1}$. Therefore, the long-run effects of inflation and inflation uncertainty on growth will be $\delta_{3} / \delta_{1}$ and $\delta_{4} / \delta_{1}$, respectively.

The results are reliable if the coefficients are structurally stable, serial correlation and heteroskedasticity are absent, the functional form of Eq. (2) is correctly specified, and there is evidence supporting cointegration. The former four conditions are tested using a battery of diagnostic tests outlined in the results section, while cointegration is tested through the joint significance of the coefficients $\delta_{1}, \delta_{2}, \delta_{3}$, and $\delta_{4}$. That is, we can verify the existence of cointegration by testing the hypothesis that $\delta_{1}=\delta_{2}=\delta_{3}=\delta_{4}=0$. Pesaran et al. (2001) have tabulated two sets of critical values under this null hypothesis. The first set of critical values are tabulated by assuming that the variables in Eq. (2) are integrated of order zero, $\mathrm{I}(0)$, while the second set are tabulated by assuming that they are integrated of order one, I(1). We can reject the presence of cointegration if the calculated F-statistic is smaller than the first set of critical values. Similarly, we fail to reject the presence of cointegration if the calculated F-statistic is larger than the second set of critical values. The test is inconclusive if the calculated F-statistic lies in-between both sets of critical values.

An issue that may still arise, thereby biasing our results, is reverse causality in the relationship between inflation uncertainty and growth. While a rise in the level of inflation uncertainty may lead to a fall in economic growth (Ball, 1992; Friedman, 1977), an improvement in economic conditions may also reduce the level of uncertainty. To address potential reverse causality, Glas and Hartmann (2016) employed an instrumental variable technique. We took this concern into consideration when using the ARDL technique. The ARDL model treats all variables as endogenous by permitting a flexible selection of the dynamic lag structure and short-run reverse causality (Ho \& Iyke, 2017; Pesaran et al., 2001, p. 299).

In addition to assessing the impact of inflation and inflation uncertainty on growth, we also want to know whether increases in inflation uncertainty have the same impact on growth as decreases. To achieve this objective, we reformulate the ARDL specification in 

Table 1. Descriptive Statistics of the Variables

\begin{tabular}{|c|c|c|c|c|}
\hline Statistics & $\ln Y$ & $\mathbf{R}$ & InINF & VOL \\
\hline Mean & 0.381 & 18.141 & 9.910 & 43.502 \\
\hline Median & 0.786 & 16.000 & 6.811 & 32.392 \\
\hline Maximum & 4.630 & 45.000 & 38.456 & 172.106 \\
\hline Minimum & -6.780 & 4.500 & -1.252 & 7.814 \\
\hline Std. Dev. & 1.956 & 10.998 & 8.649 & 35.721 \\
\hline Skewness & -1.321 & 0.800 & 1.680 & 2.130 \\
\hline Kurtosis & 5.787 & 3.000 & 5.331 & 7.215 \\
\hline Jarque-Bera & 32.602 & 5.653 & 36.941 & 79.336 \\
\hline P-value & 0.000 & 0.059 & 0.000 & 0.000 \\
\hline Sum & 20.231 & 961.500 & 525.241 & 2305.615 \\
\hline Sum Sq. Dev. & 199.114 & 6290.689 & 3890.013 & 66351.480 \\
\hline Observations & 53 & 53 & 53 & 53 \\
\hline
\end{tabular}

Note: Std. Dev. and Sum Sq. Dev. denote, respectively, standard deviation and sum of squared deviations. In denotes the natural $\log$ operator.

Error Test (RESET), the Breusch-Pagan-Godfrey test for heteroskedasticity, the Cumulative Sum of Recursive Residuals (CUSUM) test and the Cumulative Sum of Squares of Recursive Residuals (CUSUMSQ) test (see Breusch, 1978; Breusch \& Pagan, 1979; Brown, Durbin, \& Evans, 1975; Godfrey, 1978; Ramsey, 1969). It is evident from the diagnostic tests, shown at the bottom of Table 2, that the coefficients are structurally stable, there are no problems of serial correlation or heteroskedasticity, and the functional form of the model is properly specified. A rejection of serial correlation and heteroskedasticity may not necessarily imply that the iid error term assumption holds. However, at least it provides some confidence in our results. We can therefore claim that the results are reliable and can be used for prediction purposes. Additionally, the estimated error correction term is negative and statistically significant, while the F-statistic indicates the presence of cointegration at a 5\% significance level. The F-statistic is compared to Table CI(iii) Case III: Unrestricted intercept and no trend of Pesaran et al. (2001, p. 300) for three independent variables. This means that growth converges to its equilibrium level at a rate of $77.1 \%$ annually.

Let us now turn to the main results. In the short run, inflation uncertainty has differential effects on growth. That is, inflation uncertainty affects growth negatively in the current period but positively one-lag prior to this. Higher lags of inflation uncertainty do not matter for growth in the short run. In the long run, inflation uncertainty has a negative effect on growth. Similarly, inflation has a negative short-run effect on growth which is passed on as a long-run negative effect. From these results, it appears that inflation and inflation uncertainty may hurt growth both in the short and long run. This conclusion is in line with the Friedman-Ball 
Table 2. Main Results

\begin{tabular}{|c|c|c|c|c|c|c|}
\hline Lags & 0 & 1 & 2 & & & \\
\hline \multicolumn{7}{|c|}{ Selected Model: ARDL $(2,0,0,2)$} \\
\hline \multicolumn{7}{|l|}{ Short-run } \\
\hline$\Delta / n Y$ & & $0.236[1.804]$ & & & & \\
\hline$\Delta R$ & $0.003[0.148]$ & & & & & \\
\hline$\Delta / n \mathrm{INF}$ & $-0.018[-2.753]$ & & & & & \\
\hline$\triangle \mathrm{VOL}$ & $-0.008[-2.296]$ & $0.033[5.632]$ & & & & \\
\hline ECM(-1) & $-0.771[-4.606]$ & & & & & \\
\hline \multicolumn{7}{|l|}{ Long-run } \\
\hline Constant & $1.640[2.790]$ & & & & & \\
\hline $\mathrm{R}$ & $0.007[0.266]$ & & & & & \\
\hline $\ln \mid \mathrm{NF}$ & $-0.039[-2.090]$ & & & & & \\
\hline VOL & $-0.029[-2.256]$ & & & & & \\
\hline \multicolumn{7}{|c|}{ Diagnostics } \\
\hline Adj. $R^{2}$ & F-statistic & RESET & LM & BPG & CUSUM & CUSUMSQ \\
\hline 0.656 & 5.516 & 1.845(0.181) & 3.103(0.211) & $1.643(0.149)$ & S & $S$ \\
\hline
\end{tabular}

Note: The values in the block parentheses are the t-statistics. P-values for the diagnostic tests are in the parentheses. S denotes stable.

hypothesis. According to Friedman (1977), higher levels of inflation are associated with higher inflation uncertainty. This inhibits the price mechanism and long-term contracting, which in turn slows down economic activities and growth. Ball (1992) agrees with this contention by demonstrating in a formal model that high inflation generates high inflation uncertainty which translates into even higher levels of future inflation, since the public will begin to doubt the credibility of the monetary authority. Our results are also in line with the existing findings. For example, Fischer (1993), Judson and Orphanides (1999), Bhar and Mallik (2013), and Heidari et al. (2013) found a negative impact of both inflation and inflation uncertainty on growth. The results, are slightly different from those presented by Grier and Grier (2006), who found that inflation does not affect growth inversely once inflation uncertainty is accounted for. They found that the negative impact of inflation on growth is indirectly linked to inflation uncertainty. In addition to the effects of inflation and inflation uncertainty, the results show that interest rate does not affect growth either in the short or in the long run.

Could it be that these results are influenced by the maximum lag restriction or our choice of the optimal lags for each variable using the AIC? Various studies have shown that the coefficient estimates of the ARDL specification are sensitive to lag restrictions and the optimal lag selection (Halicioglu, 2007; Iyke \& Odhiambo, 2016; Tang, 2007). Therefore, we relaxed the restric- 
Table 3. Results based on Lag Restriction from Two to Three

\begin{tabular}{lcccc}
\hline Lags & 0 & 1 & 2 & 3 \\
\hline Selected Model: ARDL $(1,0,0,3)$ & & & \\
\hline
\end{tabular}

Short-run

$\Delta \operatorname{lnY}$

$\Delta R$

$\Delta / n I N F$

$\triangle \mathrm{VOL}$

$\operatorname{ECM}(-1)$

Long-run

Constant

R

InINF

VOL

Diagnostics

Adj. $R^{2}$

F-statistic

RESET

$L M$

BPG

CUSUM

CUSUMSQ

0.656

$2.039(0.160)$

$1.168(0.557)$

$1.661(0.126)$

S

S

Note: The values in the block parentheses are the t-statistics. P-values for the diagnostic tests are in the parentheses. S denotes stable.

tions in Table 2 in order to verify whether the results may change. First, we increased the maximum lag in the model from two to three and selected the optimal lags using the AIC. The resulting estimates following this adjustment are displayed in Table 3 . The preferred specification here is $\operatorname{ARDL}(1,0,0,3)$. From the diagnostic tests reported at the bottom of Table 3 , it is obvious that the coefficients are structurally stable, there are no problems of serial correlation and heteroskedasticity, and the functional form of the model is properly specified. Although, the error correction term has been reduced slightly from -0.771 to -0.728 , it is statistically significant, implying the convergence of growth to its equilibrium level annually. The calculated F-statistic also shows evidence in favor of cointegration in the model. These results are clearly reliable. Inflation uncertainty affects growth differentially in the short run by exerting a negative impact on growth in the current period, and a positive impact at one- and two-period lags. In the long run, inflation uncertainty is associated with falling growth. Inflation has both a short and a long-run negative impact on growth. These results are therefore very similar to those reported in Table 2.

In addition to adjusting the maximum lag in the model, we selected the optimal lags using the Schwarz information criterion (SIC) to verify whether the results in Table 2 will be affected. The estimated results following this adjustment are shown in Table 4. The preferred specification (i.e., $\operatorname{ARDL}(1,0,0,2))$ here is clearly different from the one shown in Table 2 (i.e., 
Table 4. Results based on selecting the Optimal Lags using SIC

\begin{tabular}{lccc}
\hline Lags & 0 & 1 & 2 \\
\hline Selected Model: ARDL $(1,0,0,2)$ & & \\
\hline
\end{tabular}

\section{Short-run}

$\Delta / n Y$

$\Delta \mathrm{R}$

$\triangle / n I N F$

$\triangle \mathrm{VOL}$

$\operatorname{ECM}(-1)$

$-0.576[-4.413]$

Long-run

Constant

$1.105[2.046]$

R

InINF

VOL

$0.014[0.358]$

$-0.044[-2.945]$

$-0.025[-2.505]$

Diagnostics

Adj. $R^{2}$

F-statistic

RESET

LM

BPG

CUSUM

CUSUMSQ

0.632

5.197

2.262(0.177)

$1.831(0.400)$

$1.696(0.146)$

S

US

Note: The values in the block parentheses are the t-statistics. P-values for the diagnostic tests are in the parentheses. S and US denote stable and unstable, respectively.

ARDL $(2,0,0,2))$. Additionally, the evidence in support of structural stability is not strong since the CUSUMSQ indicates instability. Nevertheless, the other diagnostic tests show that the results are reliable. There is also evidence in support of cointegration and convergence. Inflation uncertainty affects growth differentially in the short run, and negatively in the long run. Inflation affects growth adversely both in the short and long run. Again, these findings are fairly consistent with those reported in Table 2. Therefore, it is unlikely that the results are influenced by the maximum lag restriction and the choice of the optimal lags for each variable in the model.
Do decreases in inflation uncertainty have the same effects as increases? We explore this question by estimating Eq. (5). Following Iyke and Odhiambo (2015; 2016), we restricted the maximum lag to two and selected the optimal lag for each variable using the AIC. The results are reported in Table 5. The selected model is $\operatorname{ARDL}(2,1,0,1,2)$. The diagnostic tests, displayed at the bottom of the table, clearly suggest that these results are reliable. There is also evidence in support of cointegration and convergence. Note that the Fstatistic in Table 5 is compared to Table CI(iii) Case III: Unrestricted intercept and no trend of Pesaran et al. (2001, p.300) for four independent variables. In 
Table 5. Results based on the Nonlinear Specification

\begin{tabular}{llll}
\hline Lags & 0 & 1 & 2 \\
\hline Selected Model: ARDL $(2,1,0,1,2)$ & & \\
\hline
\end{tabular}

Short-run

$\Delta / n Y$

$\Delta R$

$\Delta / n I N F$

$\triangle \mathrm{POS}$

$\triangle N E G$

$\operatorname{ECM}(-1)$

Long-run

Constant

$-0.122[-2.393]$

R

$-0.022[-0.714]$

$\ln \mathrm{INF}$

POS

NEG

Diagnostics

Adj. R-sq.

F-statistic

RESET

LM

BPG

CUSUM

CUSUMSQ

0.843

$3.731(0.061)$

$1.439(0.486)$

$1.692(0.117)$

S

Note: The values in the block parentheses are the t-statistics. P-values for the diagnostic tests are in the parentheses. $S$ denotes stable.

the short run, increases in inflation uncertainty are associated with decreases in growth, while decreases are associated with differential responses of growth. In the long run, increases in inflation uncertainty affect growth negatively, while decreases have a positive but insignificant effect. What is clear is that in both the short and the long run, increasing inflation uncertainty is harmful for growth. A reduction in inflation uncertainty may reverse this pattern, but only slowly. Therefore, decreases in inflation uncertainty do not have the same impact as increases. With regards to the other variables, inflation has both a short and a long- run negative impact on growth, while the interest rate has a positive short-run impact on growth but a negative and insignificant impact in the long run.

In summary, the results presented above suggest that inflation uncertainty has differential effects on growth in the short run. In the long run, uncertainty has a negative effect on growth. These findings are generally consistent with the Friedman-Ball hypothesis and the findings of Fischer (1993), Judson and Orphanides (1999), and Bhar and Mallik (2013) for advanced economies. The results reflect the general performance of the Ghanaian economy during the 

Bhar, R., \& Mallik, G. (2013). Inflation uncertainty, growth uncertainty, oil prices, and output growth in the UK. Empirical Economics, 45(3), 13331350.

Blackburn, K. (1999). Can Stabilisation Policy Reduce Long-Run Growth? The Economic Journal, 109(452), 67-77.

Bredin, D., Elder, J., \& Fountas, S. (2009). Macroeconomic uncertainty and performance in Asian countries. Review of Development Economics, 13(2), 215-229.

Breusch, T. S. (1978). Testing for Autocorrelation in Dynamic Linear Models. Australian Economic Papers, 17, 334-355.

Breusch, T. S., \& Pagan, A. R. (1979). A Simple Test for Heteroskedasticity and Random Coefficient Variation. Econometrica, 47(5), 1287-1294.

Brown, R.L., Durbin, J., \& Evans, J. M. (1975). Techniques for testing the constancy of regression relations over time. Journal of the Royal Statistical Society, 37(2), 149-163.

Bruno, M., \& Easterly, W. (1998). Inflation cries and long-run growth. Journal of Monetary Economics, 41, 3-26.

Coulson, N. E., \& Robins, R. P. (1985). Aggregate economic activity and the variance of inflation: another look. Economics Letters, 17(1-2), 71-75.

De Gregorio, J. (1993). Inflation, taxation, and longrun growth. Journal of Monetary Economics, 31(3), 271-298.

Dotsey, M., \& Sarte, P. D. (2000). Inflation uncertainty and growth in a cash-in-advance economy. Journal of Monetary Economics, 45(3), 631-655.

Fischer, S. (1993). The role of macroeconomic factors in growth. Journal of Monetary Economics, 32(3), 485-512.

Fountas, S., \& Karanasos, M. (2007). Inflation, output growth, and nominal and real uncertainty: empirical evidence for the G7. Journal of International Money and Finance, 26(2), 229-250.

Fountas, S., Karanasos, M., \& Kim, J. (2002). Inflation and output growth uncertainty and their relationship with inflation and output growth. Economics Letters, 75(3), 293-301.

Friedman, M. (1977). Nobel lecture: inflation and unemployment. Journal of political economy, 85(3), 451-472.
Gillman, M., Harris, M. N., \& Mátyás, L. (2004). Inflation and growth: Explaining a negative effect. Empirical economics, 29(1), 149-167.

Glas, A., \& Hartmann, M. (2016). Inflation uncertainty, disagreement and monetary policy: Evidence from the ECB Survey of Professional Forecasters. Journal of Empirical Finance, 39, 215-228.

Gomme, P. (1993). Money and growth revisited: Measuring the costs of inflation in an endogenous growth model. Journal of Monetary economics, 32(1), 51-77.

Godfrey, L. G. (1978). Testing Against General Autoregressive and Moving Average Error Models when the Regressors Include Lagged Dependent Variables. Econometrica. 46, 1293-1301.

Grier, K. B., \& Perry, M. J. (2000). The effects of real and nominal uncertainty on inflation and output growth: some GARCH-M evidence. Journal of Applied Econometrics, 15(1), 45-58.

Grier, K. B., Henry, Ó. T., Olekalns, N., \& Shields, K. (2004). The asymmetric effects of uncertainty on inflation and output growth. Journal of Applied Econometrics, 19(5), 551-565.

Grier, R., \& Grier, K. B. (2006). On the real effects of inflation and inflation uncertainty in Mexico. Journal of Development Economics, 80(2), 478-500.

Guerrero, F. (2006). Does inflation cause poor longterm growth performance? Japan and the World Economy, 18(1), 72-89.

Gylfason, T., \& Herbertsson, T. T. (2001). Does inflation matter for growth? Japan and the World Economy, 13(4), 405-428.

Halicioglu, F. (2007). The J-curve dynamics of Turkish bilateral trade: a cointegration approach. Journal of Economic Studies, 34(2), 103-119.

Heidari, H., Katircioglu, S. T., \& Bashiri, S. (2013). Inflation, inflation uncertainty and growth in the Iranian economy: an application of BGARCH-M model with BEKK approach, Journal of Business Economics and Management, 14(5), 819-832.

Heintz, J., \& Ndikumana, L. (2011). Is there a case for formal inflation targeting in sub-Saharan Africa? Journal of African Economies, 20, ii67-ii103.

Ho, S. Y., \& Iyke, B. N. (2017). Finance-growth-poverty nexus: A re-assessment of the trickle-down hypothesis in China. Economic Change and Restructuring, 51(3), 221-247. 
Iyke, B. N., \& Ho, S. Y. (2017). The Real Exchange Rate, the Ghanaian Trade Balance, and the J-curve. Journal of African Business, 18(3), 380-392.

Iyke, B. N., \& Odhiambo, N. M. (2015). The Determinants of Long-run Real Exchange Rate in South Africa: A Fundamental Equilibrium Approach. Global Economy Journal, 15(3), 319-336.

Iyke, B. N., \& Odhiambo, N. M. (2016). Modelling long-run equilibrium exchange rate in Botswana. Macroeconomics and Finance in Emerging Market Economies, 10(3), 268-285.

Iyke, B. N., \& Odhiambo, N. M. (2017). Inflationary Thresholds, Financial Development and Economic Growth: New evidence from Two West African Countries. Global Economy Journal, 17(2), 1-11.

Judson, R., \& Orphanides, A. (1999). Inflation, volatility and growth. International Finance, 2(1), 117-138.

Khan, M., \& Senhadji, A. (2001). Threshold effects in the relationship between inflation and growth. IMF Staff Papers, 48, 1-21.

Kremer, S., Bick, A., \& Nautz, D. (2013). Inflation and growth: new evidence from a dynamic panel threshold analysis. Empirical Economics, 44(2), 861-878

Licklider, R. (1988). The Power of Oil: The Arab Oil Weapon and the Netherlands, the United Kingdom, Canada, Japan, and the United States. International Studies Quarterly, 32 (2), 205-226.

López-Villavicencio, A., \& Mignon, V. (2011). On the impact of inflation on output growth: Does the level of inflation matter? Journal of Macroeconomics, 33(3), 455-464.

Mohd, S. H., Baharumshah, A. Z., \& Fountas, S. (2013). Inflation, inflation uncertainty and output growth: recent evidence from ASEAN-5 countries. The Singapore Economic Review, 58(04), 1350030.

Mundell, R. (1963). Inflation and real interest. Journal of Political Economy, 71(3), 280-283.

Neanidis, K. C., \& Savva, C. S. (2013). Macroeconomic uncertainty, inflation and growth: Regime-dependent effects in the G7. Journal of Macroeconomics, 35, 81-92.

Owusu, M. (1989). Rebellion, revolution, and tradition: Reinterpreting coups in Ghana. Comparative Studies in Society and History, 31(2), 372-397.

Pesaran, H. M., Shin, Y., \& Smith, R. J. (2001). Bounds testing approach to the analysis of level relation- ships. Journal of Applied Econometrics, 16(3), 289-326.

Ramsey, J. B. (1969). Tests for Specification Errors in Classical Linear Least Squares Regression Analysis. Journal of the Royal Statistical Society, 31(2), $350-371$

Sarel, M. (1996). Nonlinear effects of inflation on economic growth. IMF Staff Papers, 43(1), 199-215.

Shin, Y., Yu, B. C., \& Greenwood-Nimmo, M. (2014). Modelling asymmetric cointegration and dynamic multipliers in a nonlinear ardl framework. In R. Sickels, \& W. Horrace (Eds.), Festschrift in Honor of Peter Schmidt: Econometric Methods and Applications (pp. 281-314). New York, NY: Springer.

Tang, T. C. (2007). Money demand function for Southeast Asian countries: an empirical view from expenditure components. Journal of Economic Studies, 34(6), 476-496.

Temple, J. (2000). Inflation and growth: stories short and tall. Journal of Economic Surveys, 14(4), $395-$ 426.

Tobin, J. (1965). Money and economic growth. Econometrica, 33(4), 671-684.

Tommasi, M. (1994). The consequences of price instability on search markets: Toward understanding the effects of inflation. The American Economic Review, 84(5), 1385-1396.

Ungar, M., \& Zilberfarb, B. Z. (1993). Inflation and its Unpredictability--Theory and Empirical Evidence. Journal of Money, Credit and Banking, 25(4), 709-720.

Yilmazkuday, H. (2013). Inflation Thresholds and Growth. International Economic Journal 27(1), 1-10.

\section{Endnotes}

1 One of the reviewers provided us this insight. 
